\title{
Halo Evolution of Hypereutectic Al-17.5Si Alloy Treated with High-Current Pulsed Electron Beam
}

\author{
L. Hu, B. Gao, J. K. Lv, S. C. Sun, Y. Hao, and G. F. Tu \\ School of Materials and Metallurgy, Northeastern University, Shenyang 110004, China \\ Correspondence should be addressed to B. Gao; surfgao@aliyun.com
}

Received 14 November 2014; Revised 24 February 2015; Accepted 5 March 2015

Academic Editor: Thierry Grosdidier

Copyright ( $2015 \mathrm{~L}$. Hu et al. This is an open access article distributed under the Creative Commons Attribution License, which permits unrestricted use, distribution, and reproduction in any medium, provided the original work is properly cited.

\begin{abstract}
Halo evolution of an Al-17.5Si alloy surface after treatment with increasing pulse numbers of a high-current pulsed electron beam (HCPEB) was investigated. A halo is a ring microstructure resembling a bull's eye. SEM results indicate that the nanocrystallization of halo induced by HCPEB treatment leads to gradual diffusion of the Si phase. Multiple pulses numbers cause the Si phase to be significantly refined and uniformly distributed. In addition, nanosilicon particles with a grain size of $30 \sim 100 \mathrm{~nm}$ were formed after HCPEB treatment, as shown by TEM observation. XRD results indicate that Si diffraction peaks broadened after HCPEB treatment. The microhardness tests demonstrate that the microhardness at the midpoint from the halo edge to center decreased sharply from 9770.7 $\mathrm{MPa}$ at 5 pulses to $2664.14 \mathrm{MPa}$ at 25 pulses. The relative wear resistance of a 15 -pulse sample is effectively improved by a factor of 6.5 , exhibiting optimal wear resistance.
\end{abstract}

\section{Introduction}

In certain hypereutectic alloys, it has been often observed that a layer of a second phase, known as a halo, forms around primary phases under specific environmental conditions [1]. In the early 1960s, Sundquist et al. [2] studied microstructures in four kinds of eutectic alloy systems, characterizing halo formation in terms of different undercoolings for the nucleation of two phases. If a large undercooling was required for the nucleation of the second phase in alloy, there was a corresponding formation of a large halo; if little undercooling was applied, a small halo was generated. Gigliotti et al. [3] interpreted halo formation in terms of relative growth velocity of different phases at a given undercooling. This interpretation was constructed on the competitive growth model of eutectic and halo phases. They found that a nonfaceted phase halo formed around the faceted primary phase in faceted-nonfaceted alloy systems.

The principle of the competitive growth model states that after primary phase nucleation, the liquid composition moves down the liquidus curve and its metastable extension until the second phase is nucleated. If the liquid composition does not fall in the coupled zone, the second phase has a higher growth velocity at this particular temperature and a halo will form. If the liquid composition falls inside the coupled zone, coupled growth can begin immediately and a halo will not form. Yilmaz and Elliott [4] interpreted the formation of $\mathrm{Al}$ halos in pure $\mathrm{Al}-\mathrm{Si}$ and $\mathrm{Sr}$ modified Al$\mathrm{Si}$ alloys during directional solidification by means of this model, where an $\mathrm{Al}$ halo was formed around eutectic Si and primary Si. Suk et al. $[1,5]$ also proposed a modified model to interpret the formation mechanism of halo dendrites. They reckoned that the growth temperature for the halo phase is much higher than the coupled eutectic growth but lower than the primary phases. The model explains not only the general halo formation, but also a few exceptional cases: nonfaceted halos around the nonfaceted primary phase and faceted halos around the faceted primary phase. However, Nave et al. [6] questioned these experimental results due to the measured growth temperature of halos above the equilibrium eutectic temperature at low growth rates. In response, they developed a new model for halo formation in hypereutectic alloys under directional solidification and then applied the model to verify the experimental results of Yilmaz and Elliott. Additionally, $\mathrm{Li}$ et al. [7] investigated halo formation in hypereutectic Ni$24.19 \mathrm{Nb}$ alloys under directional solidification and observed 
the critical pulling velocities of halo formation. At a pulling velocity of $10 \mu \mathrm{m} / \mathrm{s}$, halo $\alpha$-Ni dendrites were formed from the $\mathrm{Ni}$-rich solute neighbor of the primary $\beta-\mathrm{Ni}_{3} \mathrm{Nb}$ phase, which was then followed by coupled eutectic growth. The critical pulling velocity deviated only slightly from the calculated value of the model proposed by Nave et al. The model also predicted that, within an alloy matrix, $\alpha$-Ni halos would not appear at a $\mathrm{Nb}$ composition below $23.35 \%$.

In this paper, halo formation on the surfaces of hypereutectic Al-17.5Si alloys was observed and characterized after bombardment with a high-current pulsed electron beam (HCPEB). HCPEB bombardment has been investigated as a potential method for surface modification of materials in recent years [8-12]. Alloy surfaces are prone to nanocrystallization due to the rapid melting and cooling processes induced by HCPEB. A cooling rate of $10^{7} \sim 10^{9} \mathrm{~K} / \mathrm{s}$ has been attained during the treatment process $[13,14]$. The literature $[13,15-17]$ reports that halo microstructures are comprised of nanosilicon particles having formation mechanisms distinct from the ones described above. The formation mechanisms of halos are explained in terms of halo diffusion mechanisms that were first proposed by Hao [17]. They suggested that the remelting of the primary $\mathrm{Si}$ phase during the HCPEB treatment process induced diffusion of $\mathrm{Al}$ and $\mathrm{Si}$, and, afterwards, the halo structure was maintained at room temperature after rapid solidification. However, the intricacies of the mechanisms of halo generation have yet to be elucidated. In this study, we characterized halo evolution on Al-17.5Si alloy surfaces that were subjected to HCPEB treatment with an increasing series of pulse numbers. The subsequent effects of halo evolution on microhardness and wear resistance of the material surface were also investigated.

\section{Experimental}

Al-17.5Si alloy is categorized as a cast alloy with a nominal composition of $17.5 \mathrm{wt} \% \mathrm{Si}, \mathrm{Al}$ balance. Before HCPEB treatment, the samples were cut into cylinders with diameters of $10 \mathrm{~mm}$ and heights of $9 \mathrm{~mm}$. Then, the samples were ground with sandpaper and sequentially polished using abrasive pastes. Finally, HCPEB treatment was carried out using a "Nadezhda-2" source with the following experiment parameters: an accelerating voltage of $23 \mathrm{kV}$, energy density of $3 \mathrm{~J} / \mathrm{cm}^{2}$, pulse width of $1 \mu \mathrm{s}$, and a series of pulse numbers of 5,15 , and 25 , respectively.

The halo evolution on the modified alloy surface was investigated using a field emission gun scanning electron microscope (SEM) (JSM $6500 \mathrm{~F}$ ). Thin films for transmission electron microscopy (TEM) were prepared by grinding, dimpling, and ion-beam thinning; the microstructure characteristics were observed with the transmission electron microscope (Tecnai G220). The phase change was analyzed with a PW3040/60 X-ray diffractometer (XRD) and the Vickers microhardness test was conducted with the 401MVDTM. The halo microhardness was measured at the midpoint from the halo edge to center. Five points for every sample were obtained, from which the microhardness value was taken using the average value. The applied load and time during the microhardness test were $10 \mathrm{~g}$ and $10 \mathrm{~s}$, respectively. Wear tests under dry conditions were conducted using a friction and wear testing machine of high speeds and temperature (model MG-2000) at room temperature $\left(25^{\circ} \mathrm{C}\right)$. Wear resistance was represented as abrasion loss. Triplicate trials were run for each pulse number, and the average value was obtained. The untreated and HCPEB-treated samples that had $6 \mathrm{~mm}$ diameters and $12 \mathrm{~mm}$ lengths were prepared for the wear tests. Stainless steel $(1 \mathrm{Cr} 18 \mathrm{Ni}$ ) $)$ was used as the sliding counterpart dish in all tests. The surface hardness and roughness of stainless steel were $192 \mathrm{HV}$ and $1 \mu \mathrm{m}$ $\left(R_{a}\right)$, respectively. The applied load was $10 \mathrm{~N}$. The sliding speed and distance were maintained at $0.8 \mathrm{~m} / \mathrm{s}$ and $0.38 \mathrm{~km}$, respectively.

\section{Results and Discussion}

3.1. Halo Microstructure of an Al-17.5Si Alloy Surface after HCPEB Treatment. Figure 1 shows morphology micrographs of an Al-17.5Si alloy surface before and after HCPEB treatment. In Figure 1(a), it can be seen that the microstructure of the Al-17.5Si alloy before HCPEB treatment was composed of a coarse primary Si phase and eutectic structure $\left[\alpha_{(\mathrm{Al})}+\beta_{(\mathrm{Si})}\right]$. After HCPEB treatment of 15 pulses, the halo microstructure was observed, as shown in Figure 1(b). The microstructure formed was in the shape of a bull's eye. From this figure, it is observed that some microcracks exist in HCPEB-treated alloy surface, due to high brittleness of primary $\mathrm{Si}$ and the release of residual stress induced by HCPEB. The existence of microcracks severely affects material properties, especially corrosion resistance of materials. Therefore, removement of microcracks will become a key in the future work.

3.2. The Effect of Pulse Number on Halo Microstructure of Al-17.5Si Alloy Surface. Figure 2 shows SEM micrographs of halo evolution of a HCPEB-treated Al-17.5Si alloy surface under different pulse numbers. Because different atomic numbers of $\mathrm{Al}$ and $\mathrm{Si}$ elements lead to different contrasts in SEM images, the dark oblate feature is silicon phase. In Figure 2, it is observed that $\mathrm{Al}$ and $\mathrm{Si}$ in the edge and interior of halo microstructures are continually interdiffused after HCPEB treatment. This phenomenon can be explained with the HCPEB-induced rapid heating and cooling process $\left(10^{7} \sim\right.$ $10^{9} \mathrm{~K} / \mathrm{s}$ ) under a high energy density $[13,15]$. During the $\mathrm{HCPEB}$ process, interdiffusion of $\mathrm{Al}$ and $\mathrm{Si}$ elements occurs around the primary $\mathrm{Si}$ phase in the melting state. And then, due to subsequent super-rapid solidification, there is not enough time for the $\mathrm{Al}$ and $\mathrm{Si}$ elements to be redistributed and be back to their original states. Consequently, the special halo microstructure is obtained on the top treated surface. And, in $[15,16]$, it is found that $\mathrm{Al}$ and Si elements centering on the primary Si phase are distributed continuously from the center to edge of the halo by means of an electron probe microanalysis (EPMA). In addition, $\mathrm{Si}$ atoms gradually diffuse into the $\mathrm{Al}$ matrix, and the diffusion behavior of $\mathrm{Al}$ atoms is similar to that of $\mathrm{Si}$ atoms, due to the chemical potential gradient between the primary $\mathrm{Si}$ phase and the Al matrix. Therefore, the interdiffusion phenomenon of elements induced by HCPEB is a common fact, and thus 


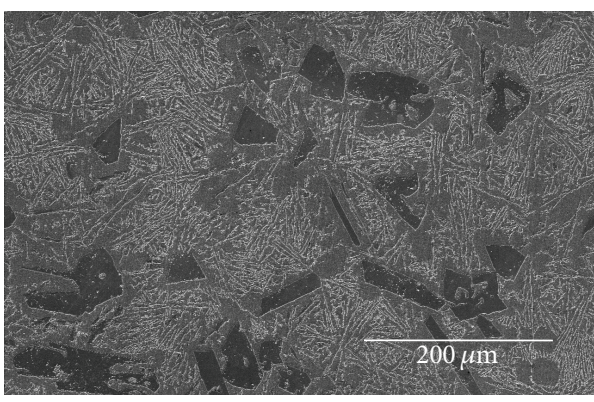

(a) Initial sample

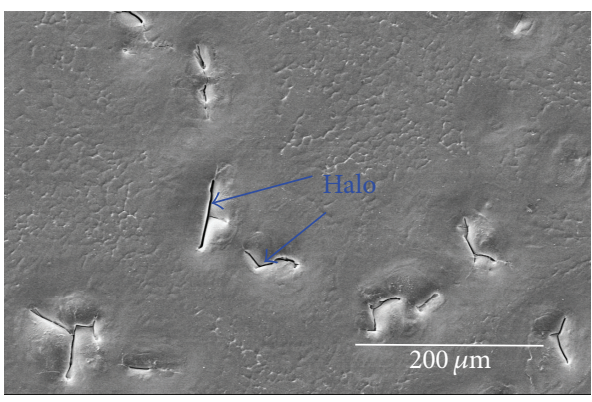

(b) 15 pulses

FIGURE 1: Morphology micrographs of Al-17.5Si alloy surfaces before and after HCPEB treatment.

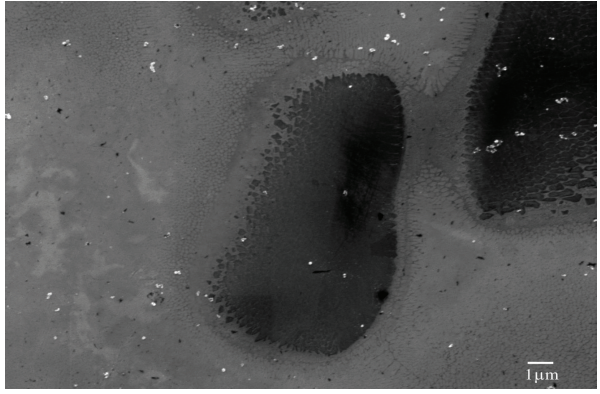

(a) 5 pulses at low magnification

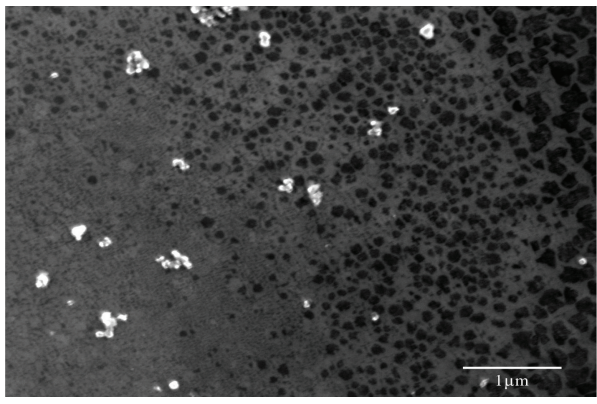

(c) 15 pulses at high magnification

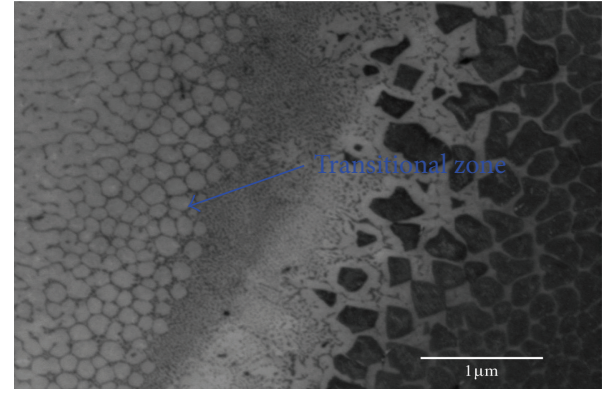

(b) 5 pulses at high magnification

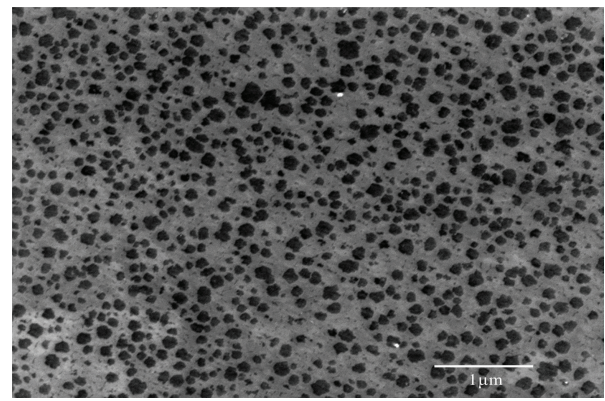

(d) 25 pulses at high magnification

FIGURE 2: SEM micrographs of halo of HCPEB-treated Al-17.5Si alloy under different pulse numbers.

the formation mechanism of halo is also called a halo diffusion mechanism. The mechanism can be summarized as follows: the remelting of the primary Si phase during the HCPEB treatment process leads to interdiffusion of $\mathrm{Al}$ and $\mathrm{Si}$, after which the halo structure was retained at room temperature after rapid solidification. In contradiction to Yilmaz and Elliott [4], the observed halo formation did not fit previously proposed mechanisms of dendritic $\mathrm{Al}$ halo formation in binary Al-Si alloys. A possible explanation is that the former concerns Si halo formation induced by HCPEB treatment, whereas the latter describes Al halo formation; that is, an $\mathrm{Al}$ phase develops around a primary $\mathrm{Si}$ phase at a certain growth velocity.

It can be seen from Figures 2(a)-2(d) that the primary Si phase forms a typical halo microstructure after HCPEB treatment where its spinous edges dissipate to form a ring, and the grains are significantly refined and uniformly distributed. The grains sizes are from $200 \sim 500 \mathrm{~nm}$, formed after
5 pulses, to nearly $70 \mathrm{~nm}$ after 25 pulses. This phenomenon indicates a diffusion trend of $\mathrm{Si}$ towards the $\mathrm{Al}$ matrix. Note that the $\mathrm{Al}$ phase in the Al-rich region presents nanocellular structures with a length of 200 300 nm under low pulses, the transitional zone indicated by a blue arrow between Al-rich and Si-rich regions is a eutectic structure $\left[\alpha_{(\mathrm{Al})}+\right.$ $\left.\beta_{(\mathrm{Si})}\right]$, and the Si phase in the Si-rich region also presents nanosilicon particles with a length of $200 \sim 500 \mathrm{~nm}$, as shown in Figure 2(b). Moreover, the distinct boundary between two phases is also observed in this figure, which demonstrates the beginning of interdiffusion of $\mathrm{Al}$ and Si elements. Under high pulses, $\mathrm{Al}$ and $\mathrm{Si}$ components fully interdiffused, with the $\mathrm{Si}$ phase homogeneously distributed in the $\mathrm{Al}$ matrix.

During the HCPEB treatment process, the alloy surface temperature increases causing the surface layer to remelt rapidly under the high heating rate $\left(10^{9} \mathrm{~K} / \mathrm{s}\right)$ [17]. Under each pulse bombardment, the Al-17.5Si alloy surface experiences 


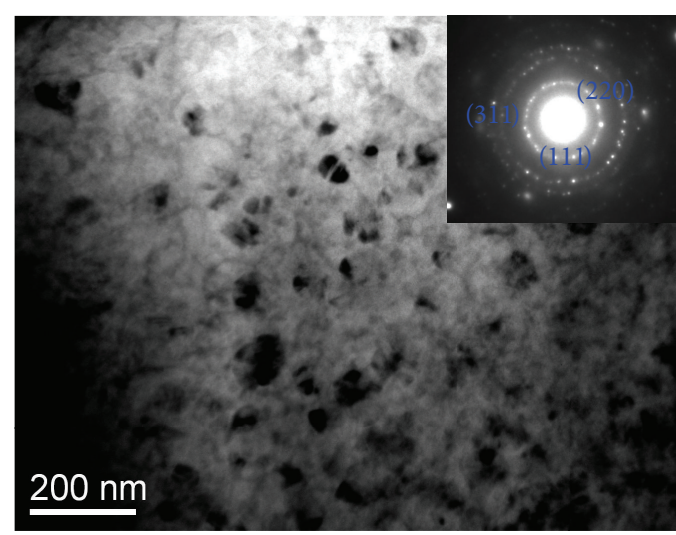

$\begin{array}{ll}\Delta & \mathrm{Al} \\ - & \mathrm{Si}\end{array}$

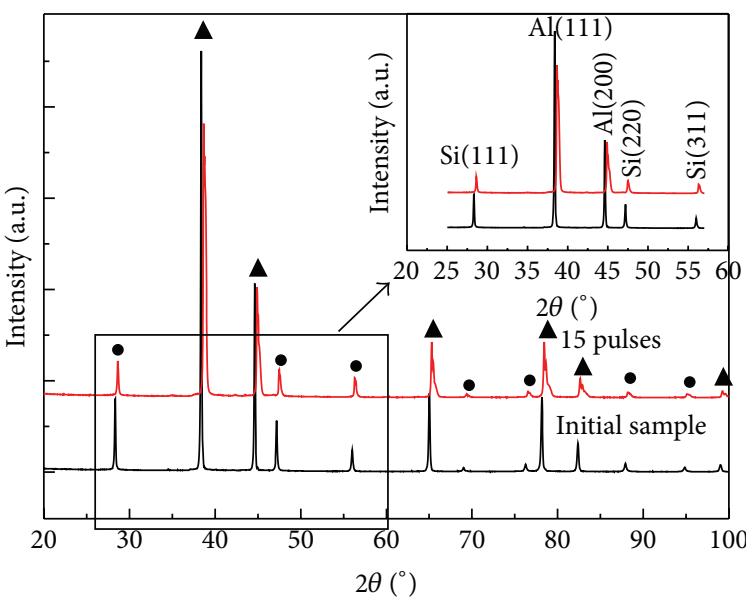

(a)

(b)

FIGURE 3: TEM bright-field image and XRD pattern of Al-17.5Si alloy after HCPEB treatment with 15 pulses: (a) TEM bright-field image and (b) XRD pattern of alloy surface after HCPEB treatment with 15 pulses.

a rapid heating and cooling process, causing the $\mathrm{Al}$ and $\mathrm{Si}$ components to quickly interdiffuse. The effect of element interdiffusion induced by HCPEB is divided into two steps: (1) element interdiffusion during the remelting process of alloy and (2) the formation of nanoparticles after cooling process of alloy. Thus, the surface composition tends to display a uniform distribution after HCPEB induced element interdiffusion. After multiple pulses, the $\mathrm{Al}$ and $\mathrm{Si}$ phases are completely diffused. The previously described phenomena corroborate the rationale of the halo diffusion mechanism.

\subsection{TEM Analysis of Al-17.5Si Alloy Surface after HCPEB} Treatment. Figure 3 shows nanosilicon in a Si-rich area and the phase change after HCPEB treatment of the Al17.5Si alloy surface. Figure 3(a) shows nanoparticles with a grain size of $30 \sim 100 \mathrm{~nm}$ distributed on the alloy surface that was subjected to 15 pulses. A corresponding SAED pattern indicates a typical polycrystalline diffraction ring. By means of diffraction ring standardization, it can be confirmed that these nanoparticles distributed on the alloy surface are nanosilicon.

Figure 3(b) shows the XRD pattern of Al-17.5Si alloy after HCPEB treatment with 15 pulses. From this figure, no new phase was observed in the XRD pattern after HCPEB treatment. This indicates that no phase transition of the diffusion occurred during the diffusion process of HCPEB-induced halo formation. In the local enlargement of Figure 3(b), it can be seen that Si diffraction peaks broaden after HCPEB treatment. The phenomenon demonstrates that $\mathrm{Si}$ phase of the alloy surface is dramatically refined.

3.4. The Effect of Pulse Number on Halo Microhardness of the Al-17.5Si Alloy Surface. Figure 4 shows the change in

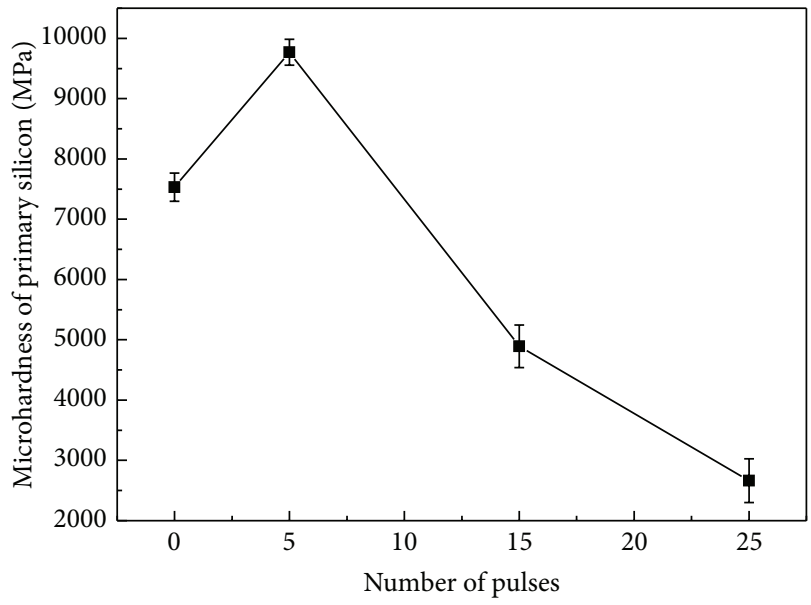

FIGURE 4: The change in microhardness of halo in an Al-17.5Si alloy surface before and after HCPEB treatment.

microhardness of the halo microstructure on the HCPEBtreated Al-17.5Si alloy surface with regard to the number of pulses. The average value of microhardness in the primary Si phase is $7531.5 \mathrm{MPa}$ without HCPEB treatment, while the microhardness value increased to $9770.7 \mathrm{MPa}$ after 5 pulses. This change is closely related to both the distribution of crystal defects and the residual stresses of the material [18]. However, the halo microhardness decreased sharply from 9770.7 $\mathrm{MPa}$ at 5 pulses to $2664.14 \mathrm{MPa}$ at 25 pulses. This is due to the diffusion of the primary Si phase into the Al matrix during the HCPEB treatment process. Alloy Surface. Figure 5 shows the change of abrasion loss of 


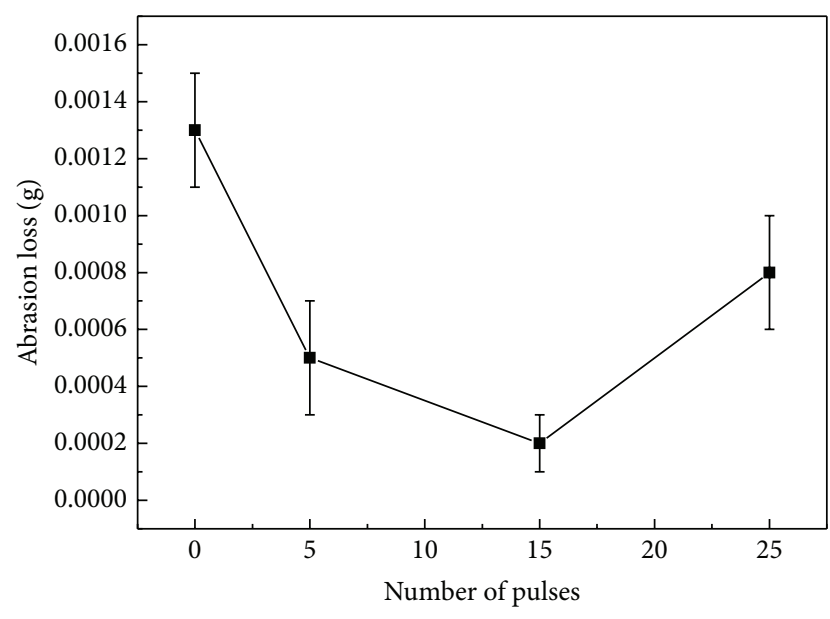

FIGURE 5: The change in abrasion loss of an Al-17.5Si alloy surface before and after HCPEB treatment.

the Al-17.5Si alloy surface with regard to the change in pulse number. Wear resistance of alloy surfaces is characterized by abrasion loss; lower abrasion loss indicates better wear resistance. In Figure 5, it is indicated that the abrasion loss of alloy surface decreases after HCPEB treatment but then increases with an increasing number of pulses. Samples subjected to 15 pulses demonstrated the lowest abrasion loss $(0.0002 \mathrm{~g})$ and hence an optimal wear resistance.

The wear resistance of materials is affected by the microstructure performance, hardness, and surface roughness of materials. Furthermore, other factors, such as the magnitude of friction force, environment temperature of abrasion behavior, and presence or absence of lubricant, determine wear resistance of materials [19]. As previously iterated in Section 3.2, the HCPEB treatment promotes diffusion of the primary $\mathrm{Si}$ phase into the neighboring $\mathrm{Al}$ matrix, with full dissolution apparent after 25 pulses. The interdiffused $\mathrm{Si}$ on the alloy surface promotes a decrease in hardness of the primary $\mathrm{Si}$ (halo microstructure). The embedded Si structures within the Al matrix behave as hard nuclei to resist abrasive action and augment material wear resistance after HCPEB treatment.

A contradiction in the formation of desired parameters was observed in this study. Although the HCPEB 15-pulse sample demonstrated the best wear resistance, its hardness was much lower than that of the 5-pulse sample. This discrepancy is attributed to a change in primary Si morphology. After 25 pulses, the primary Si phase was fully dissolved within the Al matrix, leading to the decrease of hardness in primary $\mathrm{Si}$ phase. Although this diffusion increases the hardness of the Al matrix, its hardness is much lower than that of primary $\mathrm{Si}$ as a hard phase. In summation, HCPEB treatment was shown to improve material wear resistance while impairing the hardness parameters. This change of wear resistance in $\mathrm{Al}$ 17.5Si alloy surfaces after pulse treatment is corroborated by other studies that characterized changes in HCPEB-treated AZ91 HP magnesium alloy and FeCrNi coating [19, 20].

\section{Conclusions}

(1) Halos were generated on the Al-17.5Si alloy surface after HCPEB treatment. HCPEB induces halo formation on modified surface due to the interdiffusion effect of elements. The Si phase in the halo was significantly refined and uniformly distributed.

(2) Nanosilicon particles with a grain size of 30 100 nm were formed on the alloy surface and were observed by TEM. The above obtained result is consistent with that of nanosilicon diffraction peaks in XRD analysis; that is, the Si diffraction peaks broadened.

(3) The microhardness at the midpoint from the halo edge to center decreased sharply from $9770.7 \mathrm{MPa}$ at 5 pulses to $2664.14 \mathrm{MPa}$ at 25 pulses.

(4) The result of wear resistance test indicates that abrasion loss of the alloy surface at 15 pulses is minimum (0.0002 g), exhibiting optimal wear resistance. Compared to the initial sample, the wear resistance of the 15-pulse sample was improved by a factor of 6.5.

\section{Conflict of Interests}

The authors declare that there is no conflict of interests regarding the publication of this paper.

\section{Acknowledgments}

This study was supported by the Natural Science Foundation of Shenyang City (F12-277-1-55), the Program for Excellent Talents in the Liaoning Province (LJQ2012021), and the Fundamental Research Funds for the Central Universities (N130402004).

\section{References}

[1] M. J. Suk, G. H. Choi, and I. H. Moon, "Formation of halo in $\mathrm{Sb}-\mathrm{InSb}$ and $\mathrm{Sn}-\mathrm{Bi}$ eutectic alloy systems," Journal of Crystal Growth, vol. 123, no. 1-2, pp. 5-16, 1992.

[2] B. E. Sundquist, R. Bruscato, and L. F. Mondolfo, "The structure of eutectics," Journal of the Institute of Metals, vol. 91, pp. 204208, 1962.

[3] M. F. X. Gigliotti, G. A. Colligan, and G. L. F. Powell, "Halo formation in eutectic alloy systems," Metallurgical Transactions, vol. 1, no. 4, pp. 891-897, 1970.

[4] F. Yilmaz and R. Elliott, "Halo formation in Al-Si alloys," Metal Science, vol. 18, no. 7, pp. 362-366, 1984.

[5] M. J. Suk and K. Leonartz, "Halo growth during unidirectional solidification of camphor-naphthalene eutectic system," Journal of Crystal Growth, vol. 213, no. 1, pp. 141-149, 2000.

[6] M. D. Nave, A. K. Dahle, and D. H. St John, "Halo formation in directional solidification," Acta Materialia, vol. 50, no. 11, pp. 2837-2849, 2002.

[7] S. M. Li, B. L. Jiang, B. L. Ma, and H. Z. Fu, "Halo formation in directional solidification of $\mathrm{Ni}-\mathrm{Ni}_{3} \mathrm{Nb}$ hypereutectic alloy," Journal of Crystal Growth, vol. 299, no. 1, pp. 178-183, 2007.

[8] Y. Xu, Y. Zhang, S. Z. Hao et al., "Surface microstructure and mechanical property of WC-6\% Co hard alloy irradiated by high current pulsed electron beam," Applied Surface Science, vol. 279 , pp. 137-141, 2013. 
[9] J. J. Hu, G. B. Zhang, H. B. Xu, and Y. F. Chen, "Microstructure characteristics and properties of $40 \mathrm{Cr}$ steel treated by high current pulsed electron beam," Materials Technology, vol. 27, no. 4, pp. 300-303, 2012.

[10] F. Xu, G. Guo, G. Tang et al., "Microstructure modifications and corrosion behaviors of $\mathrm{Cr} 4 \mathrm{Mo} 4 \mathrm{~V}$ steel treated by high current pulsed electron beam," Materials Chemistry and Physics, vol. 126, no. 3, pp. 904-908, 2011.

[11] T. Grosdidier, J. X. Zou, B. Bolle, S. Z. Hao, and C. Dong, "Grain refinement, hardening and metastable phase formation by high current pulsed electron beam (HCPEB) treatment under heating and melting modes," Journal of Alloys and Compounds, vol. 504, supplement 1, pp. S508-S511, 2010.

[12] M. C. Li, S. Z. Hao, and C. Dong, "Improved wear resistance of magnesium alloys AZ91 by high current pulsed electron beam treatment," Transactions of the Indian Institute of Metals, vol. 62, no. 4-5, pp. 485-487, 2009.

[13] Y. Hao, B. Gao, G. F. Tu, S. W. Li, S. Z. Hao, and C. Dong, "Surface modification of Al-20Si alloy by high current pulsed electron beam," Applied Surface Science, vol. 257, no. 9, pp. 39133919, 2011.

[14] S. Z. Hao, S. Yao, J. Guan, A. Wu, P. Zhong, and C. Dong, "Surface treatment of aluminum by high current pulsed electron beam," Current Applied Physics, vol. 1, no. 2-3, pp. 203-208, 2001.

[15] Y. Hao, B. Gao, G. F. Tu, S. W. Li, C. Dong, and Z. G. Zhang, "Improved wear resistance of Al-15Si alloy with a high current pulsed electron beam treatment," Nuclear Instruments and Methods in Physics Research, Section B: Beam Interactions with Materials and Atoms, vol. 269, no. 13, pp. 1499-1505, 2011.

[16] B. Gao, Y. Hao, W. F. Zhuang et al., "Study on continuous solid solution of $\mathrm{Al}$ and $\mathrm{Si}$ elements of a high current pulsed electron beam treated hypereutectic Al-17.5\%Si alloy," Physics Procedia, vol. 18, pp. 187-192, 2011.

[17] Y. Hao, Study on surface microstructure and properties of hypereutectic Al-Si alloy after high current pulsed electron beam treatment [Ph.D. dissertation], Northeastern University, 2012, (Chinese).

[18] S. Z. Hao, Surface modification of pure aluminum by high current pulsed electron beam [Ph.D. dissertation], Dalian University of Technology, 2000, (Chinese).

[19] D. Y. He, Surface microstructure and properties of arc-sprayed $\mathrm{FeCrAl}$ and $\mathrm{FeCrNi}$ coatings induced by high current pulsed electron beam treatment [M.S. Dissertation], Dalian University of Technology, 2011, (Chinese).

[20] B. Gao, S. Z. Hao, J. X. Zou, W. Wu, G. Tu, and C. Dong, "Effect of high current pulsed electron beam treatment on surface microstructure and wear and corrosion resistance of an AZ91HP magnesium alloy," Surface \& Coatings Technology, vol. 201, no. 14, pp. 6297-6303, 2007. 

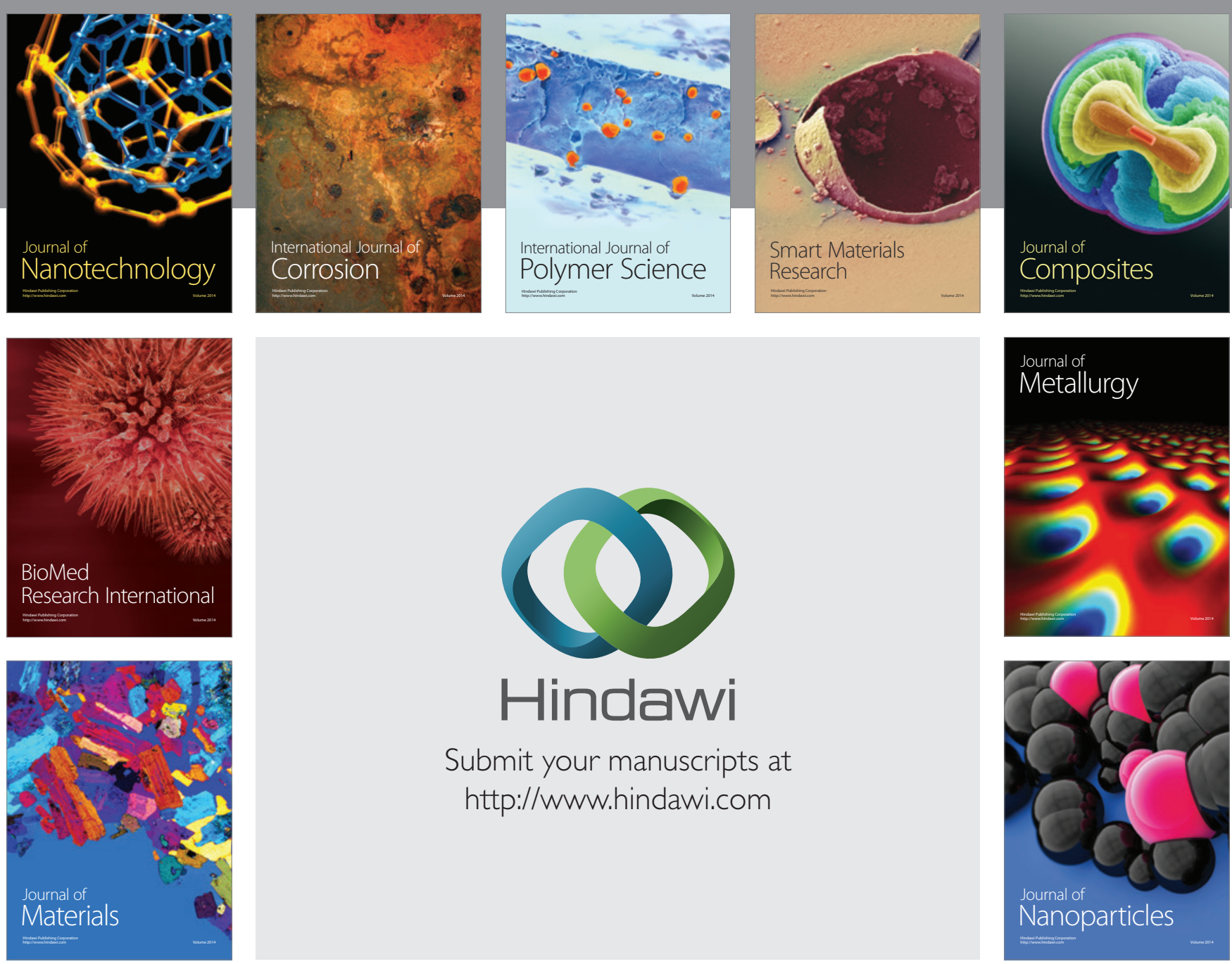

Submit your manuscripts at http://www.hindawi.com
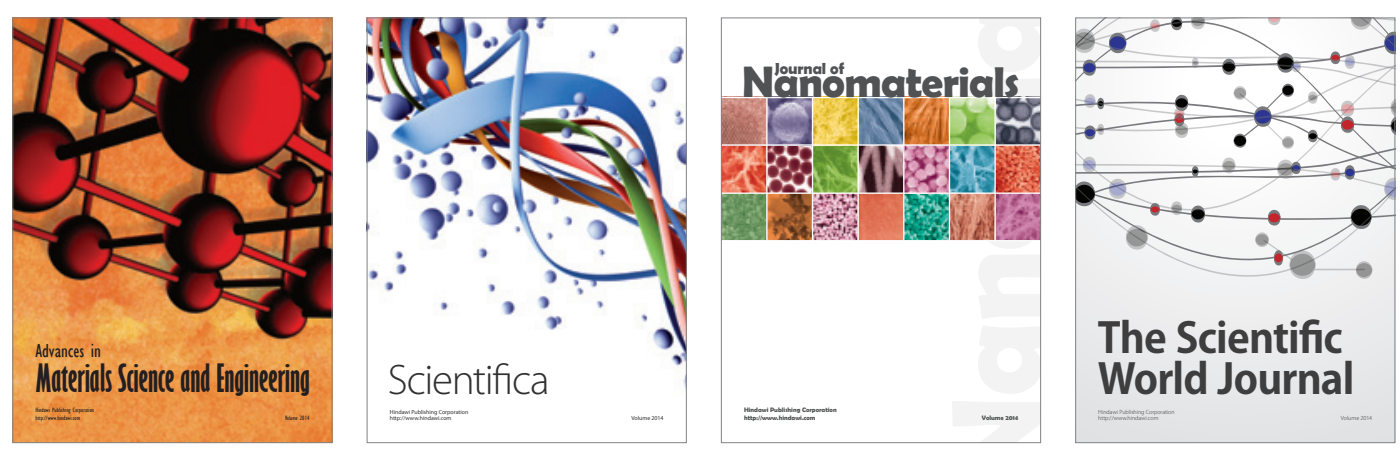

\section{The Scientific World Journal}
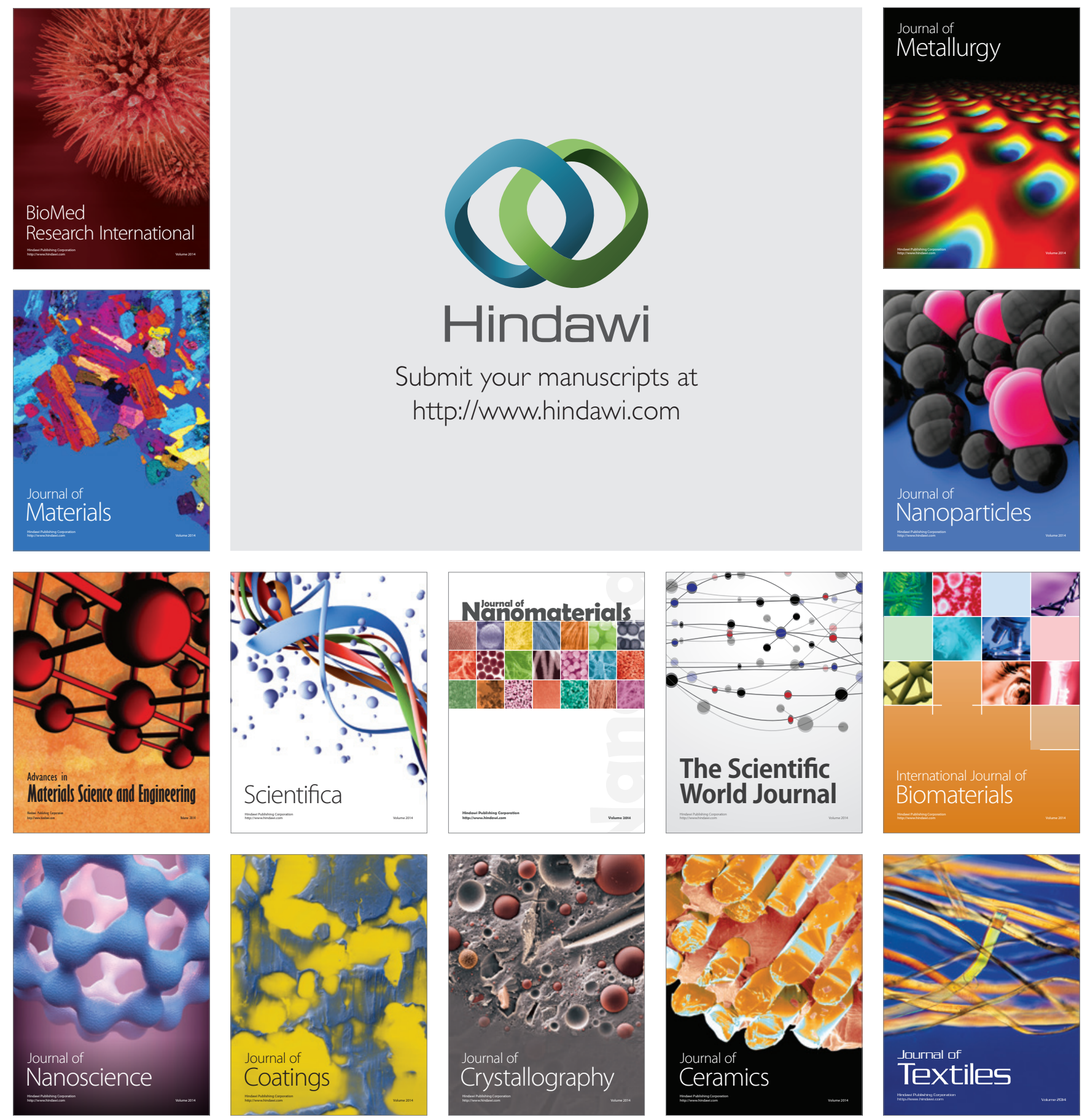